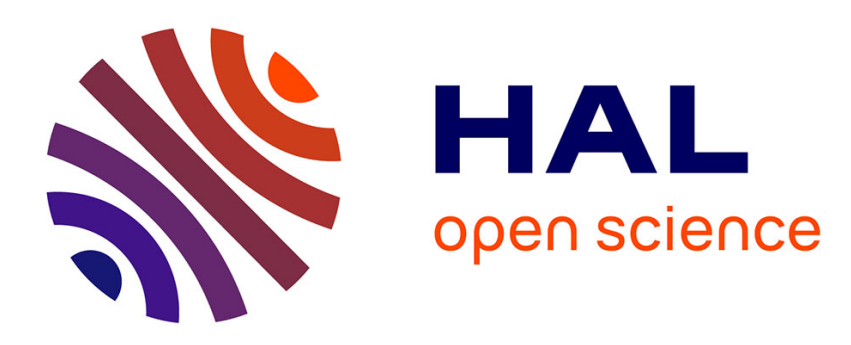

\title{
Influence of the surface-like volume elasticity on the critical thickness of a hybrid aligned nematic cell
}

\author{
G. Barbero, A. Strigazzi
}

\section{To cite this version:}

G. Barbero, A. Strigazzi. Influence of the surface-like volume elasticity on the critical thickness of a hybrid aligned nematic cell. Journal de Physique Lettres, 1984, 45 (17), pp.857-862. 10.1051/jphyslet:019840045017085700 . jpa-00232422

\section{HAL Id: jpa-00232422 https://hal.science/jpa-00232422}

Submitted on 1 Jan 1984

HAL is a multi-disciplinary open access archive for the deposit and dissemination of scientific research documents, whether they are published or not. The documents may come from teaching and research institutions in France or abroad, or from public or private research centers.
L'archive ouverte pluridisciplinaire HAL, est destinée au dépôt et à la diffusion de documents scientifiques de niveau recherche, publiés ou non, émanant des établissements d'enseignement et de recherche français ou étrangers, des laboratoires publics ou privés. 
Classification

Physics Abstracts

$61.30-68.10 \mathrm{C}$

\title{
Influence of the surface-like volume elasticity on the critical thickness of a hybrid aligned nematic cell (*)
}

\author{
G. Barbero and A. Strigazzi \\ Laboratoire de Physique des Solides, Université de Paris-Sud, Bât. 510, 91405 Orsay Cedex, France, \\ and Dipartimento di Fisica, Politecnico di Torino, C. so Duca degli Abruzzi 24, \\ I-10129 Torino, Italy
}

(Reçu le 17 avril 1984, accepté le 2 juillet 1984)

\begin{abstract}
Résumé. - L'existence d'une épaisseur critique pour une cellule nématique avec orientation hybride a été récemment démontrée en employant la théorie élastique de Frank. Ici nous analysons comment l'épaisseur critique dépend de l'élasticité de volume du type surface et nous trouvons de nouvelles limites pour $K_{13}$ en fonction des constantes élastiques principales.

Abstract. - The existence of a critical thickness for a hybrid aligned nematic cell has been recently predicted on the basis of the Frank elasticity. The purpose of the present work is to show the dependence of the critical thickness on the surface-like volume elasticity and to find new limits for $K_{13}$ in terms of the principal elastic constants.
\end{abstract}

\section{Introduction.}

During the last several years the Hybrid Aligned Nematic (HAN) cell has been considered by several authors, both for the possibility of realizing new types of coloured displays $[1,2]$ and from a fundamental point of view. In fact the HAN configuration appears suitable for measuring the elastic ratio between the splay - and bend elastic constants $K_{11} / K_{33}$ by means of dielectric [3] and optical methods [4] in the case of strong anchoring; and a HAN cell subjected to suitable external fields presents interesting flexoelectrical properties $[5,6]$. Moreover, a light beam travelling in a HAN cell can be self-focused [7].

On the other hand, the usual weak anchoring conditions strongly affect the HAN cell behaviour, determining the presence of a critical thickness, below which the cell dramatically goes to a homeotropic $(\mathrm{H})$ or to a planar $(\mathrm{P})$ configuration. This critical behaviour has been calculated in an approximate way by Labes [8] and in a rigorous way in reference [9] by taking into account only the Frank elasticity, and has been shown experimentally for the first time in the reference [10].

Nevertheless, the surface-like volume elasticity $[11,12]$ has been demonstrated to play an important role in the case of weak anchoring [13-17]. The aim of the present work is to show the

(*) Research partially supported by GNSM of Italian CNR through a coordinate contract with Calabria University, and by Centro Ricerche FIAT S.p.A. 
influence of the second order elasticity on the critical thickness of a HAN cell, and to point out some inequalities which the second-order elastic constant $K_{13}$ must satisfy.

\section{Theory.}

Let us consider a HAN cell of thickness $d$; the $z$-axis is chosen so as to be normal to the cell plates, and the anchoring conditions at $z=0, z=d$ are $\mathrm{H}$ and $\mathrm{P}$ respectively.

For simplicity, we suppose the $\mathrm{H}$-anchoring to be strong(silane anchoring) and the $\mathrm{P}$-anchoring weak with respect to the azimuth $\varphi$, the angle between the director $\mathbf{n}$ and the $z$-axis (grease anchoring with rubbing [10]). By taking into account only the first order elasticity, the critical thickness of such a HAN cell yields $d_{\mathrm{c}}=L_{33}$, where $L_{33} \equiv K_{33} / W_{\mathrm{a}}$, the de Gennes-Kléman $[18,19]$ extrapolation distance at the P-surface and $W_{\mathrm{a}}$ is the anchoring energy anisotropy $[9,20]$.

Notice that if $d<d_{\mathrm{c}}$ the whole sample has no distortion $(\varphi=0$ for any $z$ in the range $\{0, d\})$. Of course $d_{\mathrm{c}}=L_{33}$ is obtained, following the model $F_{\mathrm{s}}\left(\varphi_{\mathrm{P}}\right)=(1 / 2) W_{\mathrm{a}} \cos ^{2} \varphi_{\mathrm{P}}$ for the free energy density at the P-surface [21-23].

Let us now consider the complete expression of the free energy density $[11,12,24]$ :

$$
f=(1 / 2)\left[K_{11}(\operatorname{div} \mathbf{n})^{2}+K_{33}(\mathbf{n} \wedge \operatorname{rot} \mathbf{n})^{2}\right]+K_{13} \operatorname{div}(\mathbf{n} \cdot \operatorname{div} \mathbf{n}) .
$$

The term with $K_{22}$ has been omitted, because we refer to an ideal HAN cell with no-twist; on the other hand, the contribution of the term involving $K_{24}$ is identically zero, if the sample distortion is dependent only on the $z$-coordinate (see Appendix 1).

Hence the free energy in the absence of external fields is given by :

$$
F=(1 / 2) K_{33} \int_{0}^{d}\left(1-K \sin ^{2} \varphi\right)(\mathrm{d} \varphi / \mathrm{d} z)^{2} \mathrm{~d} z+F_{\mathrm{s}}^{(2)}\left(\varphi_{\mathrm{P}}\right)
$$

where $K \equiv 1-K_{11} / K_{33}$ is the elastic anisotropy, and the surface free energy, complete to second order, is obtained as

$$
F_{\mathrm{s}}^{(2)}\left(\varphi_{\mathrm{P}}\right)=F_{\mathrm{s}}\left(\varphi_{\mathrm{P}}\right)-(1 / 2) K_{13} \sin 2 \varphi_{\mathrm{P} \cdot}(\mathrm{d} \varphi / \mathrm{d} z)_{\mathrm{P}} .
$$

By minimizing equation (2), the Euler-Lagrange equation is obtained in the same form resulting in the case of the first-order elasticity $[11,12]$, since the term involving $K_{13}$ affects only the boundary conditions.

Hence we deduce [3]

$$
\left(1-K \sin ^{2} \varphi\right)(\mathrm{d} \varphi / \mathrm{d} z)^{2}=c^{2}
$$

being $c$ a convenient integration constant, given by

$$
\left\{\begin{array}{l}
c=I_{K}\left(\varphi_{\mathrm{P}}\right) / d \\
I_{K}\left(\varphi_{\mathrm{P}}\right) \equiv \int_{0}^{\varphi_{\mathrm{P}}}\left(1-K \sin ^{2} \varphi\right)^{1 / 2} \mathrm{~d} \varphi .
\end{array}\right.
$$

By substituting equation (5) into equation (4), the derivative $d \varphi / d z$ is obtained, and equation (2) becomes

$$
F\left(\varphi_{\mathrm{P}}\right)=F_{\mathrm{s}}\left(\varphi_{\mathrm{P}}\right)+(1 / 2 d) I_{K}\left(\varphi_{\mathrm{P}}\right)\left\{K_{33} I_{K}\left(\varphi_{\mathrm{P}}\right)-K_{13} \sin 2 \varphi_{\mathrm{P}} /\left(1-K \sin ^{2} \varphi_{\mathrm{P}}\right)^{1 / 2}\right\}
$$


We point out that in the one-constant approximation equation(4) gives

$$
\mathrm{d} \varphi / \mathrm{d} z=c, \quad \text { i.e. } \varphi=\varphi_{\mathrm{P}} z / d .
$$

Consequently equation (6) becomes $F\left(\varphi_{\mathrm{P}}\right)=F_{\mathrm{s}}\left(\varphi_{\mathrm{P}}\right)+(1 / 2 d)\left\{K_{33} \varphi_{\mathrm{P}}^{2}-K_{13} \varphi_{\mathrm{P}} \sin 2 \varphi_{\mathrm{P}}\right\}$, since the volume term is proportional to $\int_{0}^{d}(\mathrm{~d} \varphi / \mathrm{d} z)^{2} \mathrm{~d} z$. Whence equation (3) giving the equivalent surface free energy is obtained as $F_{\mathrm{s}}^{(2)}\left(\varphi_{\mathrm{P}}\right)=F_{\mathrm{s}}\left(\varphi_{\mathrm{P}}\right)-(1 / 2 d) K_{13} \varphi_{\mathrm{P}} \sin 2 \varphi_{\mathrm{P}}$.

We observe that the surface orientation is connected to the second-order elasticity of the nematic liquid crystal (NLC) : on the other hand, as pointed out by Nehring and Saupe [11], the easy direction at the surface is dependent both on the substrate treatment and on the particular NLC involved. Now, instead of calculating directly from (2) and (3) the equation expressing the boundary condition [13-17, 24] (since it would be difficult to obtain in this case [25]) we note that to find the boundary condition, it is enough to minimize the free energy $F\left(\varphi_{\mathrm{P}}\right)$ as a function of the parameter $\varphi_{\mathrm{P}}$, summarizing the anchoring effect at the wall. In other words,

$$
\mathrm{d} F / \mathrm{d} \varphi_{\mathrm{P}}=0
$$

allows us to get quickly a relatively simple relation, describing the boundary condition.

In fact, by using equation (6), after a trivial calculation we obtain, by taking into account the properties of the functions defined by means of integrals [26] :

$$
\begin{aligned}
\mathrm{d} F_{\mathrm{s}} / \mathrm{d} \varphi_{\mathrm{P}}+K_{33}(1 & \left.-K \sin ^{2} \varphi_{\mathrm{P}}\right)^{1 / 2} I_{K}\left(\varphi_{\mathrm{P}}\right) / d-(1 / 2 d) K_{13} \sin 2 \varphi_{\mathrm{P}}\left\{1+\left[2 /\left(\tan 2 \varphi_{\mathrm{P}} \times\right.\right.\right. \\
& \left.\left.\left.\times\left(1-K \sin ^{2} \varphi_{\mathrm{P}}\right)^{1 / 2}\right)+K \sin 2 \varphi_{\mathrm{P}} /\left(2\left(1-K \sin ^{2} \varphi_{\mathrm{P}}\right)^{3 / 2}\right)\right] I_{K}\left(\varphi_{\mathrm{P}}\right)\right\}=0 .
\end{aligned}
$$

Notice that such a boundary condition, influenced by the second-order elasticity, reduces to the well known equation (7.1) of reference [9], if $K_{13}=0$ and the model [21-23] for $F_{\mathrm{s}}$ is assumed.

Equation (8) is particularly useful because at this point the surface interaction function has been not yet specified : it could be of the type square-sine $[21-23,27]$ or square-sine with a correction term [28] or square-elliptic-sine [24] and so on.

If $F_{\mathrm{s}}$ is assumed to be square-sine, we may solve equation (8) obtaining the tilt angle at the $\mathrm{P}$-wall $\varphi_{\mathrm{P}}$ as a function of the nematic elasticity and the cell thickness.

To describe the asymptotic behaviour of the HAN cell, we consider a very thick sample $(d \rightarrow \infty)$ and a very thin one $\left(d \rightarrow d_{\mathrm{c}}\right)$, with $d_{\mathrm{c}}$ a priori not different from zero.

2.1 $d \rightarrow \infty$. - Since the bulk distortion density is very small, $\varphi_{\mathrm{P}} \rightarrow \pi / 2$, e.g. $\varphi_{\mathrm{P}}=\pi / 2-\varepsilon$ with $\varepsilon>0$ and $\lim _{d \rightarrow \infty} \varepsilon=0$. By expanding conveniently equation (8) around the asymptotic equilibrium configuration, we deduce

$$
\begin{aligned}
\varepsilon=(1-K)^{1 / 2} I_{K}(\pi / 2)\left\{1+\left(K_{13} / K_{33}\right) /(1-K)\right\} / \\
\\
\left\{d / L_{33}+(1-K)\left[1+2\left(K_{13} / K_{33}\right) /(1-K)\right]\right\} .
\end{aligned}
$$

Equation (9) is useful for predicting the effective tilt angle at the wall : for instance, in the case of $\operatorname{MBBA}(K \simeq 0[29])$ we deduce $\varepsilon \simeq(\pi / 2)\left(1+K_{13} / K_{33}\right)\left(L_{33} / d\right)$.

2. $2 d \rightarrow d_{\mathrm{c} .}$ - It is well known that the distortion density of a HAN cell tends to increase as the thickness becomes smaller : hence the effective tilt angle at the P-wall competitively decreases, in order to reduce the free energy of the cell.

Now, let us suppose as a working hypothesis that the critical thickness exists $[8,9]$ (in fact it has been found experimentally [10]). With the aim of finding its value, it is necessary to expand 
equation (8) with respect to the parameter $\varphi_{\mathbf{p}}$. By stopping the expansion at the third order, we get

$$
\varphi_{\mathbf{P}}^{2}=(3 / 2)\left[1-\left(L_{33}-2 L_{13}\right) / d\right] /\left\{1-\left[K L_{33}-2(2-K) L_{13}\right] / d\right\}
$$

where $L_{13} \equiv K_{13} / W_{\mathrm{a}}$.

Since birefringence measurements show that the optical path difference changes smoothly near the critical thickness [30], the following inequalities must be satisfied :

$$
\left\{\begin{array}{l}
0<L_{33}-2 L_{13} \leqslant d \\
K L_{33}-2(2-K) L_{13}<L_{33}-2 L_{13} .
\end{array}\right.
$$

This means that the critical thickness does exist, also by taking into account the second order elasticity, and is given by

$$
d_{\mathrm{c}}^{(2)}=L_{33}-2 L_{13} \text {. }
$$

On the other hand, if $K_{13}<0$ [24] the system (11) yields

$$
-K_{13}<K_{33} / 2 \text {. }
$$

Of course, if $K_{13}$ could be positive [17], equation(13) would always be satisfied. But a molecular approach $[11,12]$ shows that necessarily $K_{13}$ must be negative. Notice that equation (13) is a consequence of the hypotheses of weak $\mathrm{P}$-anchoring and strong $\mathrm{H}$-anchoring. By permuting these positions, $L_{33}$ would be replaced by $L_{11} \equiv K_{11} / W_{\mathrm{a}}$ and equation (13) would become

$$
-K_{13}<K_{11} / 2 \text {. }
$$

Obviously in this case the stable configuration below the critical thickness is the P-configuration.

We point out that equation (14) is the same as that obtained by Chigrinov et al. [24], considering the effect of an electric field producing a saturated Freedericksz transition on a NLC sample in an initial H-configuration. Notice that two different forms of the surface free energy, i.e. both square-sine and square-elliptic-sine model, result in the same inequality for $K_{13}$, consistent with the fact that $K_{13}$, although playing a surface rôle, is a bulk property, i.e. a parameter depending only on the NLC material.

It is interesting to observe that both equations (13) and (14) are necessary, since for commonly used NLC $K_{11}<K_{33}$ [31, 32], but there exist other NLC compounds exhibiting $K_{11}>K_{33}$ [3335].

Whence for a given NLC the more restrictive of the two conditions (13) and (14) must be considered.

The present analysis gives a $K$-independent limitation for $K_{13}$ due to the fact that only threshold phenomena are considered, as well as in the paper by Chigrinov et al. [24].

Moreover, the limits of the critical thickness $d_{c}^{(2)}$ are given by

$$
L_{33} \leqslant d_{c}^{(2)} \leqslant 2 L_{33}
$$

with $K_{13}<0$.

\section{Conclusions.}

The effect of the second order elasticity on the critical thickness of a HAN cell with strong anchoring on the $\mathrm{H}$-wall and weak anchoring on the P-wall has been calculated. 
While $K_{24}$ has rigorously no effect, to neglect $K_{13}$ implies in the worst case to underestimate $d_{\mathrm{c}}$ by a factor of 2 , with $K_{13}<0$.

In any case, it is important to note that the simple calculation proposed results in the conclusion that the existence of the critical thickness of a HAN cell is predictable, also by considering the second order elasticity.

On the other hand, since the effect on the critical thickness induced by neglecting $K_{13}$ is of the order of $100 \%$ at the most, $K_{13}$ is expected to influence at the same order the elasto-optical behaviour of a NLC cell, characterized by a weak anchoring. Hence, for instance, the non-linear optics behaviour of a HAN cell described in reference [7] and the optically induced Freedericksz transition introduced by Zeldovich et al. [36] and recently discussed by Ong [37] should be revised.

A similar analysis should be performed with the aim of giving a rigorous approach to the problem of the spontaneous Freedericksz transition recently discussed by Kaznacheev and Sonin [38].

Such a work is in preparation and will be presented in another paper.

\section{Acknowledgments.}

The authors are indebted to G. Durand for stimulating discussion on the subject of the form of the effective surface energy - see equation (6), giving the actual dependence of the easy axis on $K_{13}$, i.e. on the characteristics of the NLC.

Many thanks are also due to F. Simoni for the critical revision of the manuscript.

\section{Appendix 1}

The term involving the second order elasticity $K_{24}$ in the free energy density of a nematic can be written [39] :

$$
f_{24} \equiv K_{24} \operatorname{div}\{\mathbf{n} \operatorname{div} \mathbf{n}+\mathbf{n} \wedge \operatorname{rot} \mathbf{n}\}
$$

It is easy to show that $f_{24}$ gives no contribution if the distortion depends only on one coordinate, for instance on the $z$-coordinate.

In fact

$$
\left\{\begin{aligned}
\mathbf{n} \operatorname{div} \mathbf{n} & =\left(\mathrm{d} n_{z} / \mathrm{d} z\right)\left(\mathbf{i} n_{x}+\mathbf{k} n_{z}\right) \\
\mathbf{n} \wedge \operatorname{rot} \mathbf{n} & =\mathbf{i} n_{z}\left(\mathrm{~d} n_{x} / \mathrm{d} z\right)+\mathbf{k} n_{x}\left(\mathrm{~d} n_{x} / \mathrm{d} z\right)
\end{aligned}\right.
$$

hence

$$
\{\mathbf{n} \operatorname{div} \mathbf{n}+\mathbf{n} \wedge \operatorname{rot} \mathbf{n}\}=\mathbf{i}\left(n_{x}\left(\mathrm{~d} n_{z} / \mathrm{d} z\right)+n_{z}\left(\mathrm{~d} n_{x} / \mathrm{d} z\right)\right)+\mathbf{k}\left(n_{x}\left(\mathrm{~d} n_{x} / \mathrm{d} z\right)+n_{z}\left(\mathrm{~d} n_{z} / \mathrm{d} z\right)\right)
$$

giving

$$
\operatorname{div}\{\mathbf{n} \operatorname{div} \mathbf{n}+\mathbf{n} \wedge \operatorname{rot} \mathbf{n}\}=(1 / 2)\left(d^{2} / \mathrm{d} z^{2}\right)\left(n_{x}^{2}+n_{z}^{2}\right)=0
$$

\section{References}

[1] Matsumoto, S., Kawamoto, M. and Mizunaya, K., J. Appl. Phys. 47 (1976) 3842.

[2] Riva, R., Fis. Tecnol. 2 (1979) 114.

[3] Barbero, G. and StrigazZI, A., Fizika 13 (1981) 85.

[4] SCUdieri, F., Opt. Commun. 37 (1981) 37.

[5] Dozov, I., Martinot-Lagarde, Ph. and Durand, G., J. Physique Lett. 43 (1982) L-365. 
[6] Dozov, I., Martinot-Lagarde, Ph. and Durand, G., J. Physique Lett. 44 (1983) L-817.

[7] Barbero, G., Simoni, F., Appl. Phys. Lett. 41 (1982) 504 ; J. Appl. Phys. 55 (1984) 384.

[8] Hochbaum, A. and Labes, M.M., J. Appl. Phys. 53 (1982) 2998.

[9] Barbero, G. and Barberi, R., J. Physique 44 (1983) 609.

[10] Barbero, G., Madhusudana, N.V. and Durand, G., J. Physique Lett. 45 (1984) L-613.

[11] Nehring, J. and Saupe, A., J. Chem. Phys. 54 (1971) 337.

[12] Nehring, J. and Saupe, A., J. Chem. Phys. 56 (1972) 5527.

[13] Derzhanski, A.I. and Hinov, H.P., Phys. Lett. A 56 (1976) 465.

[14] Hinov, H.P., J. Physique Lett. 38 (1977) L-215.

[15] Derzhanski, A.I. and Hinov, H.P., J. Physique 38 (1977) 1013.

[16] Derzhanski, A.I., Petrov, A.G. and Mitov, M.D., J. Physique 39 (1978) 273.

[17] Hinov, H.P. and Derzhanski, A.I., J. Physique Colloq. 40 (1979) C3-305.

[18] De Gennes, P.G., The Physics of Liquid Crystals (Clarendon Press, Oxford) 1974.

[19] Kléman, M., Points, Lignes, Parois (Les Ed. de Phys., Paris) 1977 and references therein; Vitek, V. and Kléman, M., J. Physique 36 (1975) 59.

[20] Barbero, G., Bartolino, R., Mol. Cryst. Liq. Cryst. 99 (1983) 80 ;

Rapini, A. and Papoular, M., J. Physique Colloq. 30 (1969) C4-54;

Kleman, M. and Ryschenkow, G., J. Chem. Phys. 64 (1976) 404 ; J. Chem. Phys. 64 (1976) 413.

[21] Naemura, S., Mol. Cryst. Liq. Cryst. 68 (1981) 183; Appl. Phys. Lett. 33 (1978) 1 ; J. Physique Colloq. 40 (1979) C3-514.

[22] Naemura, S., Liquid Crystal Alignment Mechanism and Influence on Display Device Characteristics, preprint (1982):

StrigazzI, A. in : GNCL Cristalli Liquidi, Proceed. UNICAL 81 (CLUT, Torino) 1982, p. 543.

[23] Chigrinov, V.G., Sov. Phys. Crystallogr. 27 (1982) 245.

[24] Barnik, M.I., Blinov, L.M., Korkishko, T.V., Umansky, B.A. and Chigrinov, V.G., Mol. Cryst. Liq. Cryst. 99 (1983) 53.

[25] Barbero, G., Bartolino, R. and Meuti, M., J. Physique Lett. 45 (1984) L-449.

[26] Smirnov, V., Cours de Mathématiques Supérieures, (MIR, Moscou) 1969.

[27] MeYer, R.B., Solid State Commun. 12 (1973) 585.

Barbero, G. and Strigazzi, A., Nuovo Cimento B 69 (1981) 335.

[28] Yang, K.H., J. Appl. Phys. 53 (1982) 6742 ; Jpn J. Appl. Phys. 22 (1983) 389; Appl. Phys. Lett. 43 (1983) 171 ;

Yang, K.H. and Rosenblatt, C., Appl. Phys. Lett. 43 (1983) 62.

[29] Barbero, G., Malvano, R. and Strigazzi, A., Nuovo Cimento B 59 (1980) 367.

[30] Barbero, G., Madhusudana, N.V. and Durand, G., Z. Naturf. $A$, in press.

[31] DE Jeu, W.H., ClaAssen, W.A.P. and Spruist, A.M., Mol. Cryst. Liq. Cryst. 37 (1976) 269.

[32] SChadt, M. and MÜller, F., IEEE Trans. Electron. Dev. ED-25 (1978) 1125.

[33] DE JeU, W.H. and ClaAssen, W.A.P., J. Chem. Phys. 67 (1977) 3705.

[34] DE Jeu, W.H., Physical Properties of Liquid Crystalline Materials (Gordon and Breach, New York) 1980.

[35] Bartolino, R., Doucet, J. and Durand, G., Ann. Phys. 3 (1978) 389.

[36] Zeldovich, B. Ya and Tabiryan, N.V., Sov. Phys. JETP 55 (1982) 656 and references therein ;

Zeldovich, B. Ya, Merzlikin, S.K., Pilipetsky, N.F., Sukhov, A.V. and Tabiryan, N.V., V LC Conf. of Soc. Countries, Odessa, 1 C-54 (1983) 106.

[37] Ong, H.L., Phys. Rev. A 28 (1983) 2393.

[38] Kaznacheev, A.V. and Sonin, A.S., Fiz Tverd. Tela (Leningrad) 25 (1983) 917.

[39] Dubois-Violette, E. and Parodi, O., J. Physique Colloq. 30 (1969) C4-57. 